\title{
Estudo comparativo das proporções morfométricas entre garanhões e castrados da raça Campolina
}

\section{Comparative study of morphometric proportions among Campolina's stallions and gelded ones}

\author{
Jorge Eduardo Cavalcante Lucena ${ }^{1 *}$; Sérgio Aguiar de Barros Vianna ${ }^{2}$; \\ Felipe Berbari Neto ${ }^{3}$; Romero Luiz Mendonça Sales Filho'; \\ Wellison Jarles da Silva Diniz ${ }^{4}$
}

\section{Resumo}

\begin{abstract}
A estreita relação entre as características de exterior e a classificação funcional dos equinos tem contribuído consideravelmente no processo seletivo a partir da identificação de indivíduos morfologicamente superiores, permitindo a eliminação do processo reprodutivo de indivíduos portadores de caracteres indesejáveis. Objetivou-se avaliar as medidas lineares dos garanhões e castrados registrados no livro definitivo da ABCCCampolina, bem como compará-las e determinar as correlações existentes. Para tal, foram analisadas 15 medidas lineares de 4.837 garanhões e 1.371 castrados a partir da estatística descritiva, correlação de Pearson e análise de variância. De forma geral, as correlações encontradas apresentaram valores maiores para garanhões que para os castrados. Para aqueles a maioria das medidas foram significativamente influenciadas $(\mathrm{P}<0,01)$ pelo ano de nascimento, estado do criatório e pelagem, enquanto que para os castrados a pelagem foi a variável de menor influência $(\mathrm{P}<0,01)$ sobre as medidas. Destaca-se que a castração não comprometeu o desenvolvimento final dos animais, entretanto a falta de critérios dos produtores no momento da seleção e a preferência pessoal podem contribuir para a fixação de caracteres raciais em detrimento dos funcionais. Isso pode ser evidenciado pelo fato de os machos castrados da raça Campolina mostraram-se, em média, melhores proporcionados quando comparados aos garanhões.
\end{abstract}

Palavras-chave: ABCCCampolina, biometria, conformação, castrados, medidas lineares

\begin{abstract}
In the equine species, the surface characteristics, present a close relationship with its functional classification. The scientific use of linear measurements can contribute decisively in the selective process of many breeds, by identifying the higher morphologically individuals and excluding from reproduction those that are not closed to desirable. The present study objected to evaluate and compare, the linear measures from stallions and gelded horses registered in ABCCCampolina's CP6 and CP8 books, and to determinate the existing correlations. In order to reach so, 15 linear measures from 4.837 stallions and 1.371 gelded were evaluated from descriptive statistic, Pearson's correlation and analysis of variance. Generally, higher values of correlations were observed for stallions than to gelded ones. To stallions, most of the measures were significantly influenced $(\mathrm{P}<0,01)$ by the year of birth, state of birth and coat
\end{abstract}

\footnotetext{
${ }^{1}$ Profs., Universidade Federal Rural de Pernambuco, Unidade Acadêmica de Garanhuns, FRPE-UAG, Garanhuns, PE. E-mail: jorgelucena245@hotmail.com; romero.sfilho@gmail.com

2 Prof., Universidade Estadual do Norte Fluminense Darcy Ribeiro, UENF, Campos dos Goytacazes, RJ. E-mail: vianna@uenf.br

3 Prof., Universidade Federal do Espírito Santo, UFES. Vitória, ES. E-mail: berbarineto@hotmail.com

${ }^{4}$ Discente de Graduação em Zootecnia, UFRPE-UAG. Garanhuns, PE. E-mail: wjarles09@gmail.com

* Autor para correspondência
} 
color, while to gelded ones the coat color showed lower influence $(\mathrm{P}<0,01)$ upon the measures. It's important to notice that castration did not committed the animal's final growth, however the breeders non sense the lack of appropriated criteria during the selection process and personal preferences can contribute towards stablishing breed characters rather than functionals. This can be highlighted by the fact that Campolina's gelded horses showed, in average, better proportioned than stallions.

Key words: ABCCCampolina, biometry, conformation, gelded, linear measures

\section{Introdução}

A raça Campolina caracteriza-se por apresentar animais de elevado porte, robustez, resistência e de andamento cômodo (ABCCC, 2006). É uma raça de origem nacional de equinos marchadores, utilizada para sela, trabalho e lazer (ABCCC, 1995) cuja recente origem, datada do final do século XIX, e as constantes mudanças promovidas pelo apelo mercadológico, contribuíram para que seu padrão racial e funcional sofressem diversas alterações durante todo este período. Uma vez que, na espécie equina, existe uma alta correlação entre características físicas e sua função produtiva, o estudo da proporcionalidade das partes, em cavalos marchadores, é importante na contribuição do aperfeiçoamento funcional.

De acordo com Barbosa (1993), a existência de associações entre a morfologia e a função dos equinos implica na necessidade de realização de avaliações morfométricas adequadas para estes animais. $\mathrm{O}$ estudo das mensurações das regiões do corpo dos animais pode ser definido tanto como biometria quanto como morfometria, envolvendo aspectos importantes das regiões anatômicas (BRETAS, 2006).

O estudo das proporções, na avaliação morfológica dos animais, baseia-se nas relações existentes entre as diversas regiões do corpo e o conjunto formado por elas. O animal é considerado bem-proporcionado, se as partes do corpo, observadas em conjunto, são adaptadas à função destinada, como sela, esporte ou tração, no caso dos equinos (COSTA et al., 1998). Em virtude destes apresentarem uma alta dependência da harmonia entre as suas partes e da qualidade de ligação das mesmas, para desempenhar suas funções específicas, Barbosa (1993) afirmou que as partes do animal devem ser analisadas não apenas de forma isolada, mas também na função, na dinâmica e harmonia do corpo do animal como um todo.

Lesbre (1920) baseado no comprimento da cabeça estabeleceu para cavalos adultos mediolíneos, eumétricos e de sela, um sistema eclético de proporcionalidade: onde o comprimento do pescoço, da espádua, do dorso-lombo, da garupa e do corpo guardam as seguintes relações, respectivamente: $1 ; 1 ; 5 / 6 ; 5 / 6$ e $2.1 / 2$.

As elevadas correlações fenotípicas entre as medidas lineares indicam que existe alta correlação entre as características de conformação (CABRAL, 2002). Portanto, é necessário que haja conhecimento não apenas das regiões isoladas do corpo do equino ou mesmo da harmonia entre elas, mas também, é importante que se conheça o quanto cada característica está correlacionada com outra.

No primeiro estudo morfométrico sobre a raça Campolina, Fontes (1957) observou correlações entre altura de cernelha e comprimento do corpo de 0,580 , altura na cernelha e perímetro torácico de 0,676 e entre comprimento do corpo e perímetro torácico de -0,240, para machos acima de 5 anos, sendo sempre significativos, exceto a relação entre comprimento do corpo e perímetro torácico, que foi não-significativa.

A pouca utilização de provas e índices zootécnicos na seleção dos equinos no Brasil contribui muitas vezes para a castração de indivíduos que poderiam contribuir para o melhoramento genético de um rebanho ou raça. Especificamente na raça Campolina, o empirismo aplicado na seleção 
e a influência mercadológica exercida ao longo do tempo, podem ter contribuído para a castração de indivíduos de alto valor genético.

Desta forma, objetivou-se avaliar as medidas lineares dos garanhões e castrados registrados no livro definitivo da ABCCCampolina, bem como compará-las e determinar as correlações existentes entre estas medidas.

\section{Material e Métodos}

Os dados utilizados neste trabalho foram cedidos pela Associação Brasileira de Criadores do Cavalo Campolina, a partir dos Registros Definitivos de Garanhões e Registros Definitivos de Castrados acima de 36 meses da categoria Puros de Origem, respectivamente inscritos nos livros de registro CP5 e CP8. Foram utilizados dados de 4.837 garanhões, nascidos entre os anos de 1963 e 2006 e de 1.371 castrados, nascidos entre os anos de 1977 e 2006.

As informações obtidas junto ao banco de dados foram: data de nascimento, data da mensuração, pelagem, estado do criatório, além das medidas lineares referentes a cada animal, a saber:

- Altura na Cernelha (ACER): Altura na região interescapular, distância entre as extremidades livres do $5^{\circ}$ ou $6^{\circ}$ processos espinhosos das vértebras torácicas e o solo;

- Altura no Dorso (ADOR): Distância entre a extremidade livre dos processos das vértebras torácicas, $\mathrm{T} 12$ ou T13, e o solo;

- Altura na Garupa (AGAR): Distância entre o ponto mais alto da transição lombo-sacra e o solo;

- Altura dos Costados (ACOS): Distância entre os processos espinhosos das vértebras torácicas, T12 ou T13, e o processo xifóide das esternébras;

- Comprimento da Cabeça (CCAB): Distância entre a extremidade labial cranial e a borda posterior do osso occipital da cabeça;

- Comprimento do Pescoço (CPES): Distância entre a porção cranial da face lateral da asa do Atlas e a borda cranial do terço médio do músculo supra-espinhoso;

- Comprimento de Dorso-Lombo (CDL): Distância entre os processos espinhosos da vértebra torácica T8 e da vértebra lombar L6;

- Comprimento de Garupa (CGAR): Distância entre a porção cranial da face lateral da tuberosidade ilíaca, tubérculo coxal, e a tuberosidade isquiática da pelve;

- Comprimento de Espádua (CESP): Distância entre a porção central da extremidade proximal da cartilagem escapular e o centro da articulação escápulo-umeral;

- Comprimento de Corpo (CCOR): Distância entre a borda cranial da articulação escápuloumeral e a tuberosidade isquiática da pelve;

- Largura de Cabeça (LCAB): distância entre as extremidades distais dos processos zigomático-frontais ou supra-orbitários direito e esquerdo;

- Largura de Peito (LPEI): Distância entre os tubérculos maiores laterais dos úmeros direito e esquerdo;

- Largura de Ancas (LANC): Distância entre as proeminências mais laterais das tuberosidades ilíacas, tuberosidades coxais, direita e esquerda;

- Perímetro Torácico (PTOR): A fita métrica deve ser colocada circundando o tórax, fazendo contato com a extremidade livre do processo espinhoso de $\mathrm{T} 11$ e a região do $9^{\circ}$ espaço intercostal;

- Perímetro de Canela (PCAN): passa-se a fita métrica no terço médio do III metacarpiano.

Do conjunto de dados fez-se a eliminação de valores discrepantes originados a partir de erros 
de digitação no banco de dados, seguida de análise exploratória com o intuito de descrever de maneira geral os dados biométricos do estudo. Nesta análise foram obtidas medidas de posição: média, moda, mediana e medidas de dispersão: coeficiente de variação.

O coeficiente de correlação de Pearson foi utilizado para verificar a intensidade da correlação existente entre as medidas lineares, assim como um teste para verificar a significância da correlação também foi efetuado. As análises desse trabalho executadas a partir do software estatístico SPSS 17.

Após as análises descritivas, os dados relativos às medidas lineares foram submetidos à análise de variância segundo o modelo:

$Y_{i j k l}=\mu+\alpha_{i}+\beta_{j}+\gamma_{k}+\varepsilon_{i j k l}$

onde:

$\mu=$ constante geral;

$\alpha_{i}=$ efeito relativo ao ano de nascimento $i$;

$\beta_{\mathrm{j}}=$ efeito relativo ao estado de localização do criatório j;

$\gamma_{\mathrm{k}}=$ efeito relativo ao tipo de pelagem $\mathrm{k}$;

$\varepsilon_{\mathrm{ijkl}}=$ erro aleatório associado à cada observação.

Verificou-se, portanto, se as várias medidas lineares e os diversos índices morfométricos apresentam diferenças significativas em suas médias conforme varia o ano de nascimento, o estado de origem do criatório e o tipo de pelagem. A análise de variância foi realizada empregando-se somas de quadrados do tipo II (LITTELL; FREUND; SPECTOR, 1991). As Médias para os diferentes níveis dos fatores ano de nascimento, estado de origem do criatório e pelagem, foram estimadas por procedimentos de mínimos quadrados (SILVA, 1993). Após a análise de variância, os dados foram submetidos ao teste de Tukey.

\section{Resultados e Discussão}

Os dados, referentes às medidas lineares, dos animais castrados do Livro CP8 e dos garanhões do Livro CP5, revelados neste estudo foram comparados entre si e também comparados com dados de estudos anteriores, sobretudo abordando dados dos garanhões da raça Campolina. Esta comparação visou elucidar como é feito o trabalho de seleção dos criadores da raça e que tipos de animais são excluídos, pelo método da castração.

Observando a Tabela 1, percebe-se que para o parâmetro ACER, a média encontrada para os castrados, de 1,575 m, é inferior a dos garanhões, de $1,598 \mathrm{~m}$. O valor médio encontrado neste estudo, para ACER, dos garanhões da raça, é maior que o encontrado por Fontes (1957) de $1,548 \mathrm{~m}$, em estudo abordando exclusivamente garanhões da mesma raça em estudo, acima de 5 anos, e também em relação ao encontrado por Berbari Neto (2005), quando este encontrou o valor médio de 1,594 m. Segundo o autor existe a tendência de aumento da ACER média dos garanhões, se aproximando cada vez mais do ideal de 1,62 m, preconizado no padrão da raça para garanhões.

Esta diferença média de pouco menos de 2,5 $\mathrm{cm}$, entre os valores encontrados, para castrados e garanhões, pode ser explicada pelos resultados do estudo de Cabrera, Costa e Fonseca (2004), que avaliaram parâmetros lineares em animais castrados e não castrados, observando que a castração não comprometeu o desenvolvimento final dos animais, que tal fato pode ser explicado pelo hábito de castração após a puberdade, praticada pelos criadores. Contudo, a maior distância da média encontrada para os castrados, em relação ao padrão da raça para machos, pode ser um dos indicativos, pelos quais estes animais tenham sido excluídos do processo seletivo da raça. 
Tabela 1. Média e coeficiente de variação (CV) para as diferentes medidas lineares (m) dos castrados e dos garanhões registrados da ABCCCampolina.

\begin{tabular}{lcccccc}
\hline \multirow{2}{*}{ Variável $^{1}$} & \multicolumn{6}{c}{ Estatística } \\
\cline { 2 - 6 } & \multicolumn{2}{c}{ Castrados } & \multicolumn{5}{c}{ Garanhões } \\
\cline { 2 - 6 } & Média & CV (\%) & N & Média & CV (\%) & N \\
\hline ACER & 1,575 & 2,838 & 1368 & 1,598 & 2,772 & 4822 \\
ADOR & 1,498 & 3,076 & 1368 & 1,518 & 2,901 & 4819 \\
AGAR & 1,567 & 3,661 & 1368 & 1,590 & 2,726 & 4809 \\
ACOS & 0,647 & 4,559 & 1368 & 0,650 & 4,662 & 4819 \\
CCAB & 0,618 & 4,254 & 1368 & 0,626 & 4,268 & 4810 \\
CPES & 0,643 & 5,086 & 1368 & 0,670 & 5,835 & 4817 \\
CDL & 0,588 & 9,302 & 1368 & 0,611 & 10,198 & 4822 \\
CGAR & 0,517 & 10,233 & 1368 & 0,537 & 6,697 & 4822 \\
CESP & 0,565 & 7,423 & 1368 & 0,588 & 6,697 & 4814 \\
CCOR & 1,592 & 3,429 & 1368 & 1,621 & 3,584 & 4820 \\
LCAB & 0,211 & 4,869 & 1365 & 0,217 & 5,059 & 4814 \\
LPEI & 0,401 & 7,049 & 1368 & 0,419 & 6,637 & 4808 \\
LANC & 0,519 & 5,040 & 1367 & 0,530 & 4,888 & 4812 \\
PTOR & 1,817 & 3,803 & 1367 & 1,839 & 3,868 & 4814 \\
PCAN & 0,194 & 6,099 & 1367 & 0,195 & 6,119 & 4814 \\
\hline
\end{tabular}

${ }^{1} \mathrm{ACER}=$ altura de cernelha $(\mathrm{m}) ; \mathrm{ADOR}=$ altura de dorso $(\mathrm{m}) ; \mathrm{AGAR}=$ altura da garupa $(\mathrm{m}) ; \mathrm{ACOS}=$ altura de costados $(\mathrm{m}) ;$ $\mathrm{CCAB}=$ comprimento da cabeça $(\mathrm{m})$; CPES = comprimento do pescoço $(\mathrm{m})$; CDL = comprimento de dorso-lombo $(\mathrm{m})$; CGAR = comprimento da garupa $(\mathrm{m}) ; \mathrm{CESP}=$ comprimento das espáduas $(\mathrm{m}) ; \mathrm{CCOR}=$ comprimento do corpo $(\mathrm{m}) ; \mathrm{LCAB}=$ largura da cabeça $(\mathrm{m})$; LPEI = largura do peito $(\mathrm{m}) ; \mathrm{LANC}=$ largura de ancas $(\mathrm{m}) ;$ PTOR = perímetro torácico $(\mathrm{m}) ;$ PCAN = perímetro de canela $(\mathrm{m})$.

Fonte: Elaboração dos autores.

Em relação ao equilíbrio, entre ACER e AGAR, tão necessário para o bom desempenho do cavalo de marcha, os resultados observados na Tabela 1 demonstram que a média encontrada para os castrados, de AGAR foi de $1,567 \mathrm{~m}$, ou seja, um pouco menor que a observada para ACER. Para os garanhões, embora apresentam valor médio maior para ACER, quando comparados aos castrados, pode ser observado que também apresentam AGAR média menor em relação à ACER (Tabela 1). Tal diferença pode ser explicada pelo fato do ponto anatômico para a tomada da ACER ser influenciado pelo processo espinhoso das vértebras torácicas (SILVA, 2009). Contudo, o equilíbrio entre ACER e AGAR encontrado, tanto para os castrados, como para os garanhões, está dentro do recomendado pelo padrão da raça, que tolera até $2 \mathrm{~cm}$ de diferença a mais na garupa (ABCCCAMPOLINA, 2006).
Os valores observados na Tabela 1, para a média de ADOR dos castrados e garanhões, foram 1,498 e $1,518 \mathrm{~m}$, respectivamente. Estas medidas, quando relacionadas às ACER e AGAR, supracitadas, evidenciam que a proporcionalidade entre elas está de acordo com o proposto por Oom e Ferreira (1987), os quais afirmaram que a ADOR deve ser de 6 e $10 \mathrm{~cm}$ inferior às ACER e AGAR. Para esta proporcionalidade, tanto Berbari Neto (2005), quanto Campos (2006), encontraram para garanhões e fêmeas da raça Campolina proporções, entre estas medidas, dentro do recomendado.

Segundo o Sistema Eclético de Lesbre, citado por Torres e Jardim (1992), a altura de cernelha e o comprimento corpóreo devem ser proporcionais entre si, e cada um deve equivaler a duas vezes e meia o comprimento da cabeça. Na Tabela 2, pode ser observado que, tanto o garanhão quanto 
o castrado da raça Campolina, apresentam valores proporcionais para tais medidas. Contudo, os valores médios encontrados para os animais castrados, se aproximam ainda mais do recomendado, para um animal Tipo Sela, pelo Sistema Eclético de Lesbre, com relação à proporcionalidade entre $\mathrm{CCAB} /$ ACER $(2,548)$ e CCAB/CCOR $(2,576)$, quando comparado aos valores encontrados para as mesmas relações nos garanhões, quando estes apresentaram os seguintes valores: 2,552 e 2,590, respectivamente.

Tabela 2. Valores médios das proporções das medidas lineares $(\mathrm{m})$ em relação ao comprimento da cabeça, proposto pelo Sistema Eclético de Proporções Lineares (Lesbre) dos castrados e dos garanhões registrados da ABCCCampolina.

\begin{tabular}{lccc}
\hline Variável & $\begin{array}{r}\text { Sistema } \\
\text { Eclético }\end{array}$ & Castrados & Garanhões \\
\hline CCAB & 1,000 & 1,000 & 1,000 \\
ACER & 2,500 & 2,548 & 2,552 \\
AGAR & 2,500 & 2,535 & 2,540 \\
CCOR & 2,500 & 2,576 & 2,590 \\
CPES & 1,000 & 1,040 & 1,070 \\
CESP & 1,000 & 0,914 & 0,939 \\
CDL & 0,833 & 0,951 & 0,976 \\
CGAR & 0,833 & 0,836 & 0,858 \\
LCAB & 0,333 & 0,341 & 0,346 \\
LANC & 0,833 & 0,840 & 0,846 \\
LPEI & 0,833 & 0,649 & 0,669 \\
\hline
\end{tabular}

$\mathrm{CCAB}=$ comprimento da cabeça; ACER = altura de cernelha; $\mathrm{AGAR}=$ altura da garupa; $\mathrm{CPES}=$ comprimento do pescoço; $\mathrm{CDL}=$ comprimento de dorso-lombo; CGAR = comprimento da garupa; $\mathrm{CESP}=$ comprimento das espáduas; $\mathrm{CCOR}=$ comprimento do corpo; LCAB = largura da cabeça; LPEI = largura do peito; LANC = largura de ancas.

Fonte: Elaboração dos autores.

Além desta proporcionalidade entre o comprimento de cabeça e as alturas de cernelha e garupa, pode ser observado na Tabela 1, que o castrado é um pouco melhor proporcionado na relação ACER/CCOR, quando comparado com as médias encontradas para os garanhões pelo preconizado por Lesbre. Para esta proporção, os castrados apresentam o CCOR em média $1,7 \mathrm{~cm}$ maior que a ACER, já os garanhões apresentam o CCOR 2,3 cm maior. Estes valores encontrados para estas proporções indicam que as mesmas não foram decisivas na escolha dos reprodutores, uma vez que para uma raça em formação, espera-se que os animais descartados do processo seletivo, apresentem características de menor qualidade.

O valor médio encontrado, dos garanhões, da variável CCOR de 1,620 m (Tabela 1), é maior que o observado por Berbari Neto (2005), quando o autor encontrou valor médio, para a mesma variável de 1,616 m. Este aumento na média do CCOR é concordante com o relato do referido autor, que constatou em seu estudo, curva crescente para esta medida, com média de 1,65 m para os últimos animais registrados no ano 2000 .

Conforme observado na Tabela 1, o comprimento médio da cabeça dos castrados da raça Campolina, de 0,618 m é menor que o observado, para os garanhões (Tabela 1) de 0,626 m. O valor encontrado para os garanhões é maior que os $0,624 \mathrm{~m}$ encontrados, por Berbari Neto (2005) em seu estudo, quando o autor constatou uma tendência de crescimento de 0,109 $\mathrm{cm}$, por ano de nascimento, para esta característica.

O menor valor encontrado para a média do $\mathrm{CCAB}$ (Tabela 1) dos animais castrados em relação aos garanhões pode ser um indicativo da má interpretação do padrão racial por parte dos selecionadores, utilizando animais com maior comprimento de cabeça na reprodução, contrariando princípios de equilíbrio e biomecânica tão importantes para animais marchadores. Cabral (2002) comenta sobre a importância do comprimento da cabeça como diferencial na expressão racial, podendo uma cabeça curta ou longa demais descaracterizar uma raça.

Além da importância da cabeça para a caracterização racial, o comprimento desta é utilizado como referencial pelo Sistema Eclético de Lesbre citado por Torres e Jardim (1992), na proporcionalidade com outras partes do corpo, tais como: CPES, CESP, CDL, CGAR, ACER, AGAR, CCOR, LCAB, LANC e LPEI (Tabela 2). 
A cabeça, também deve guardar proporcionalidade entre as suas partes. Para tal, o padrão da raça Campolina determina que a mesma seja proporcional no seu comprimento, largura e altura (ABCCAMPOLINA, 2006). Segundo Lesbre, citado por Torres e Jardim (1992), a apreciação das proporções sugere que o comprimento, apresente três vezes a medida da largura, para animais mediolíneos, Tipo Sela.

Baseado na referência supracitada pode ser observado, nos dados da Tabela 1, que a LCAB encontrada para os animais castrados da raça Campolina foi de $0,211 \mathrm{~m}$, um pouco superior à proporção desejada, para um CCAB observado de 0,618. Da mesma forma, a cabeça dos garanhões, apresentou LCAB $(0,217 \mathrm{~m})$, superior ao esperado para um CCAB de $0,626 \mathrm{~m}$.

Esta relação entre as partes da cabeça pode ser melhor observada na Tabela 2, onde os castrados apresentaram uma melhor proporcionalidade (0,341), em relação ao preconizado pelo Sistema Eclético de Lesbre (0,333), quando comparado ao valor encontrado para os garanhões de 0,346. Esta observação pode indicar que a característica LCAB não apresente, para os selecionadores, a mesma importância que o comprimento, no momento da escolha dos reprodutores.

Os valores observados para a proporcionalidade entre comprimento e largura de cabeça dos garanhões (Tabela 2), são concordantes com a tendência de diminuição da largura de cabeça, relatada por Berbari Neto (2005), quando o autor encontrou o valor de 0,36 para a referida proporção.

Os valores observados para a proporção CCAB e CPES evidenciam uma proximidade maior, do valor encontrado para os castrados $(1,040)$, em relação ao proposto pelo Sistema Eclético de Lesbre $(1,000)$, quando comparado ao valor de 1,070 para os garanhões (Tabela 2). Este valor observado para a proporção $\mathrm{CCAB} / \mathrm{CPES}$ dos garanhões é próximo ao observado por Berbari Neto (2005), quando o autor encontrou a proporção de 1,076. De acordo com Borton, citado por Cabral (2002), a cabeça e o pescoço exercem papel importante na determinação da capacidade atlética do cavalo, pois a liberdade de movimento da cabeça e do pescoço influenciam profundamente na qualidade da marcha.

A proporção observada na Tabela 2, entre o CCAB e o CESP, tanto dos garanhões, quanto dos castrados é menor que o recomendado de 1,000, por Lesbre, citado por Torres e Jardim (1992). Contudo, o valor de 0,939 , encontrado para os garanhões indica uma maior proximidade ao desejável, que os 0,914, observado para os castrados. O valor encontrado para os garanhões é discordante do encontrado por Berbari Neto (2005), quando o autor observou, para a referida proporção o valor de 0,912 , com tendência de aumento na desproporção, em virtude do aumento no CCAB e diminuição no CESP.

De acordo com Naves citado por Cabral (2002), o comprimento da espádua está diretamente relacionado com a qualidade de andamento, evidenciando que o comprimento das espáduas é fundamental para se atingir uma boa amplitude de passadas. No entanto, Bretas (2006) em estudo de correlação entre características morfométricas e cinemáticas com equinos da raça Campolina, não encontrou significância para correlações positivas entre CESP e comprimento e frequência de passadas.

Para a proporção entre o CCAB e o CDL, os valores observados na Tabela 2, evidenciam que tanto o garanhão com 0,976 , quanto o castrado com 0,951 , apresentam comprimento dorso-lombar maior, em relação aos seus respectivos comprimentos de cabeça, quando comparados com o recomendado pelo Sistema Eclético de Lesbre, citado por Torres e Jardim (1992) de 0,833. O valor encontrado para a referida proporção, nos garanhões, é concordante com o observado por Berbari Neto (2005), quando o autor encontrou para a mesma proporção nos garanhões da raça Campolina, o valor de 0,992, com tendência de diminuição da medida do CDL.

A maior proximidade dos castrados da raça Campolina, em relação ao recomendado para 
proporção de CCAB:CPES e CCAB:CDL(Tabela2), pode ser um indicativo de que essas proporções não tenham sido levadas em consideração no processo de seleção da raça, uma vez que tais medidas são de grande relevância para a funcionalidade do cavalo.

O valor médio de $0,517 \mathrm{~m}$ para CGAR, observado na Tabela 1, evidencia que os animais castrados encontram-se, para esta medida linear, bemproporcionados em relação ao seu CCAB de 0,618 m, segundo o Sistema Eclético de Lesbre, citado por Torres e Jardim (1992), apresentando uma proporção de 0,836 , muito próxima aos 0,833 , proposto pelo autor. Para os garanhões, as medidas de 0,626 m de CCAB e 0,537 m de CGAR (Tabela 8), evidenciam que o comprimento da garupa é maior que o recomendado por Lesbre, citado por Torres e Jardim (1992), para o respectivo CCAB.

O valor observado na Tabela 2, de 0,858 para a proporção $\mathrm{CCAB} / \mathrm{CGAR}$ dos garanhões, é menor que o encontrado por Berbari Neto (2005) de 0,867. Esta diminuição na proporção pode estar relacionada à tendência de diminuição do CGAR relatada pelo autor, nos animais nascidos a partir de 1993.

Em relação às medidas de CGAR e LANC, os valores observados de 0,517 e $0,519 \mathrm{~m}$, para os castrados são de 0,537 e $0,530 \mathrm{~m}$, para os garanhões (Tabela 1), evidencia que em média as garupas dos castrados e garanhões da raça Campolina, apresentam proximidade com o equilíbrio necessário de 1:1, citado por Vale (1984). Embora em proporcionalidade, castrados e garanhões apresentem proximidade, o maior comprimento e largura média observados nos garanhões, denota uma preferência por indivíduos com garupas mais longas e largas, no processo de seleção. Além disso, o manejo nutricional e atlético mais adequado, porém com maior custo, aplicado de forma mais frequente aos garanhões, podem ter contribuído com medidas como: largura de garupa e perímetro torácico, uma vez que o escore corporal tem alta correlação com tais medidas.

Santos (1981) relata que para que haja boa proporcionalidade em um cavalo, faz-se necessário um dorso-lombo curto, associado a espáduas e garupas longas. Baseado nesta citação percebe-se que tanto o castrado, quanto o garanhão Campolina, apresentam em média, medidas de dorso-lombo e espádua, pouco adequadas. No entanto, o comprimento de garupa é tido como proporcional nos castrados e considerado longo nos garanhões, em relação ao comprimento de cabeça.

Medidas como ACOS, LPEI e PTOR fornecem dados indicativos relacionados ao arqueamento de costelas, à capacidade respiratória e ao peso corporal. Com relação à LPEI observa-se que a medida encontrada para os castrados $(0,401$ $\mathrm{m})$ é ligeiramente menor que os $0,419 \mathrm{~m}$ para os garanhões (Tabela1). Berbari Neto (2005), também em estudo da raça Campolina, encontrou o mesmo valor de 0,419 m, para os garanhões.

Os valores observados para as proporcionalidades entre o CCAB e a LPEI (Tabela 2) evidenciam que tanto os garanhões $(0,669)$, mas principalmente os castrados $(0,649)$, apresentam o peito estreito quando comparados com o valor de 0,833 , preconizado por Lesbre para esta proporção. Esta observação vai de encontro ao padrão da raça Campolina, que determina que o peito seja amplo e musculoso.

Os garanhões apresentam ACOS pouco maior que os castrados, cujos respectivos valores médios são: 0,650 e 0,647 m (Tabela 1). Berbari Neto (2005) e Campos (2006) encontraram para a mesma medida, os seguintes valores médios: 0,649 e 0,650 m, para garanhões e fêmeas da raça Campolina, respectivamente. Esta medida é de grande importância, pois juntamente com a medida de perímetro torácico, fornece dados sobre a profundidade torácica (CABRAL, 2002). No mesmo estudo, Cabral (2002) encontrou para os machos da raça Mangalarga Marchador, os valores para ACOS de $0,67 \mathrm{~m}$ e para ACER de $1,515 \mathrm{~m}$, evidenciando uma maior profundidade no comparativo com os garanhões e castrados da raça Campolina.

Pode ser observado na Tabela 1 que os garanhões 
apresentam valor médio de PTOR $(1,839 \mathrm{~m})$, maior que o encontrado para os castrados de $(1,817 \mathrm{~m})$, indicando um maior arqueamento de costelas. O valor observado para os garanhões é pouco maior que o encontrado por Berbari Neto (2005) de 1,838 m e ambos são maiores que o encontrado por Fontes (1957) de 1,802 m. Este aumento observado no PTOR dos garanhões pode ser atribuído à seleção e melhoramento genético aplicados à raça Campolina, que tem no seu padrão racial o ideal para costelas definido como: bem arqueadas, proporcionando um tórax amplo e profundo.

Cabrera, Costa e Fonseca (2004), observaram que a medida do perímetro torácico e o peso vivo dos animais foram as únicas variáveis analisadas no estudo que apresentaram diferença significativa entre os grupos de castrados e não castrados. Esta citação é concordante com o relato de Reece (2006), sobre o efeito miotrópico da testosterona, provocando aumento de massa muscular nos animais inteiros.
Segundo Vale (1984) e Barbosa (1993), o PCAN deve ser largo para que haja boa implantação dos tendões, garantindo bom desenvolvimento muscular do sistema locomotor. Logo, observa-se na Tabela 1 que os valores médios encontrados para o PCAN dos castrados $(0,194 \mathrm{~m})$ e dos garanhões $(0,195 \mathrm{~m})$ são muito próximos. Como os castrados apresentam menor medida média de PTOR, é correto afirmar que, em média, este grupo de animais, apresenta uma melhor condição na relação de base de sustentação.

$\mathrm{Na}$ Tabela 3 pode ser observado que foram encontrados, como valores mínimos, medidas para ACER, abaixo das mínimas exigidas, para registro dos castrados e garanhões, de 1,50 e 1,54 $\mathrm{m}$, respectivamente. Para o registro mínimo da ADOR, dos castrados $(1,14 \mathrm{~m})$, percebe-se uma discrepância em relação a ACER e AGAR, podendo ser explicada por uma lordose acentuada, defeito classificado como não permissível, perante o padrão da raça, ou mesmo por erro de aferição.

Tabela 3. Percentis amostrais para as diferentes medidas lineares $(\mathrm{m})$ dos castrados e garanhões registrados da ABCCCampolina.

\begin{tabular}{lcccccc}
\hline & \multicolumn{7}{c}{ Pariável $^{1}$} & \multicolumn{7}{c}{ Castrados } & \multicolumn{3}{c}{ Garanhões } \\
\cline { 2 - 6 } & $0 \%$ & $50 \%$ & $100 \%$ & $0 \%$ & $50 \%$ & $100 \%$ \\
\cline { 2 - 6 } & 1,470 & 1,570 & 1,740 & 1,480 & 1,600 & 1,760 \\
ACER & 1,140 & 1,500 & 1,670 & 1,310 & 1,520 & 1,680 \\
ADOR & 1,450 & 1,570 & 1,700 & 1,460 & 1,590 & 1,740 \\
AGAR & 0,540 & 0,650 & 0,790 & 0,460 & 0,650 & 0,840 \\
ACOS & 0,500 & 0,620 & 0,700 & 0,320 & 0,630 & 0,780 \\
CCAB & 0,520 & 0,640 & 0,760 & 0,350 & 0,670 & 0,880 \\
CPES & 0,350 & 0,580 & 0,860 & 0,340 & 0,600 & 0,870 \\
CDL & 0,380 & 0,520 & 0,620 & 0,210 & 0,540 & 0,720 \\
CGAR & 0,410 & 0,560 & 1,510 & 0,210 & 0,580 & 0,760 \\
CESP & 1,420 & 1,590 & 1,810 & 1,400 & 1,620 & 1,880 \\
CCOR & 0,150 & 0,210 & 0,260 & 0,160 & 0,220 & 0,380 \\
LCAB & 0,260 & 0,400 & 0,700 & 0,290 & 0,440 & 0,580 \\
LPEI & 0,400 & 0,520 & 1,590 & 0,350 & 0,550 & 0,800 \\
LANC & 1,550 & 1,820 & 2,100 & 1,550 & 1,880 & 2,200 \\
PTOR & 0,150 & 0,190 & 0,230 & 0,160 & 0,200 & 0,280 \\
PCAN & &
\end{tabular}

${ }^{1} \mathrm{ACER}=$ altura de cernelha $(\mathrm{m}) ; \mathrm{ADOR}=$ altura de dorso $(\mathrm{m}) ; \mathrm{AGAR}=$ altura da garupa $(\mathrm{m}) ; \mathrm{ACOS}=$ altura de $\operatorname{costados}(\mathrm{m}) ; \mathrm{CCAB}=$ comprimento da cabeça $(\mathrm{m}) ; \mathrm{CPES}=$ comprimento do pescoço $(\mathrm{m}) ; \mathrm{CDL}=$ comprimento de dorso-lombo $(\mathrm{m}) ; \mathrm{CGAR}=$ comprimento da garupa $(\mathrm{m}) ; \mathrm{CESP}=$ comprimento das espáduas $(\mathrm{m}) ; \mathrm{CCOR}=$ comprimento do corpo $(\mathrm{m}) ; \mathrm{LCAB}=$ largura da cabeça $(\mathrm{m}) ; \mathrm{LPEI}=$ largura do peito $(\mathrm{m}) ; \mathrm{LANC}=$ largura de ancas $(\mathrm{m}) ; \mathrm{PTOR}=$ perímetro torácico $(\mathrm{m})$; PCAN = perímetro de canela $(\mathrm{m})$.

Fonte: Elaboração dos autores. 
Os valores máximos encontrados para ACER dos castrados $(1,74 \mathrm{~m})$ e também dos garanhões (1,76 m) (Tabela 3 ) estão bem acima do preconizado como ideal para garanhões da raça de 1,62 m. Como ambos os valores máximos e mínimos, da medida ACER, nos castrados e garanhões são relativamente próximos, demonstra que tal característica isoladamente não foi responsável pela eliminação de alguns animais do processo seletivo da raça por meio da castração.

Ainda pode ser observado para castrados valores muito baixos para as variáveis LCAB e LPEI, bem como para garanhões, para CGAR, LCAB e LPEI (Tabela 3). Estes valores não são compatíveis com cavalos adultos, sobretudo para uma raça que preconiza as proporções do tipo sela e apresenta ACER mínima de 1,50 m para os castrados e 1,54 $\mathrm{m}$ para os garanhões.

Nas Tabelas 4 e 5, observam-se fortes correlações $(\mathrm{P}<0,01)$, entre a medida de ACER em relação à $\mathrm{ADOR}$ e AGAR, com valores de 0,903 e 0,712, para os castrados e 0,908 e 0,938, para os garanhões. Outra forte correlação $(\mathrm{P}<0,01)$ foi observada para os castrados e também para os garanhões, entre as variáveis ACER e CCOR, apresentando valores de 0,737 para os castrados e 0,718. Para estas correlações, os valores encontrados por Berbari Neto (2005), em seu estudo com os garanhões da raça, foram 0,8944, 0,931 e 0,6979, respectivamente valores estes menores que os encontrados no presente estudo.

A alta correlação $(\mathrm{P}<0,01)$, observada nos garanhões (Tabela 5), entre as variáveis AGAR e ADOR, com valor de 0,898 , foi maior que o observado para os castrados (Tabela 4) cujo valor foi 0,663 . Da mesma forma, foi observado que para a correlação entre as variáveis CCOR e AGAR, os garanhões apresentaram um maior valor $(0,709)$, quando comparados aos castrados $(0,531)$. Tais resultados podem ser consequência da adoção dessas medidas no processo de seleção, levando a melhoria conjunta das medidas.
Valores de correlação medianamente fortes ( $\mathrm{P}<0,01)$ foram observados para os castrados, entre o CCAB e as seguintes medidas: ACER, ADOR, ACOS e CPES, como pode ser observado na Tabela 4. Para os garanhões (Tabela 5), observa-se que as correlações entre variáveis, classificadas como medianamente fortes $(\mathrm{P}<0,01)$, foram encontradas em maior número, sendo mais frequentes para as correlações envolvendo o CCAB e ACOS, com as medidas de ACER, ADOR, AGAR e ACOS.

Em relação à medida de $\mathrm{CDL}$, esta não apresentou correlação positiva com todas as outras medidas, no caso dos castrados (Tabela 4). Mesmo quando foram observadas correlações positivas, para esta variável, os valores observados foram fracos $(\mathrm{P}<0,01)$, para castrados e garanhões, sendo o mais alto encontrado para os castrados de 0,182 e para os garanhões de 0,403. Berbari Neto (2005) também encontrou para os garanhões da raça, correlações positivas, para esta variável, classificadas como fracas $(\mathrm{P}<0,01)$, cujo maior valor encontrado foi 0,3398 .

De forma geral, as correlações encontradas neste estudo, apresentaram valores mais baixos para os castrados que para os garanhões. Estas correlações mais baixas podem indicar uma maior heterogeneidade nos animais castrados, uma vez que o motivo da castração é bastante variável.

As características lineares ACER, ADOR, AGAR, CCAB, CPES, CDL, CCOR, LCAB, LANC e PCAN para os castrados deste estudo (Tabela 6), foram influenciadas significativamente $(\mathrm{P}<0,01)$ pelo ano de nascimento. Para ACOS, também foi observada influência do ano de nascimento, contudo com significância de 5\% $(\mathrm{P}<0,05)$. As demais medidas lineares não apresentaram sofrer influência significativa do ano de nascimento.

Para os garanhões as quinze medidas biométricas (Tabela 6) foram significativamente influenciadas $(\mathrm{P}<0,01)$ pelo ano de nascimento, concordando com o observado por Berbari Neto (2005), em seu estudo. 


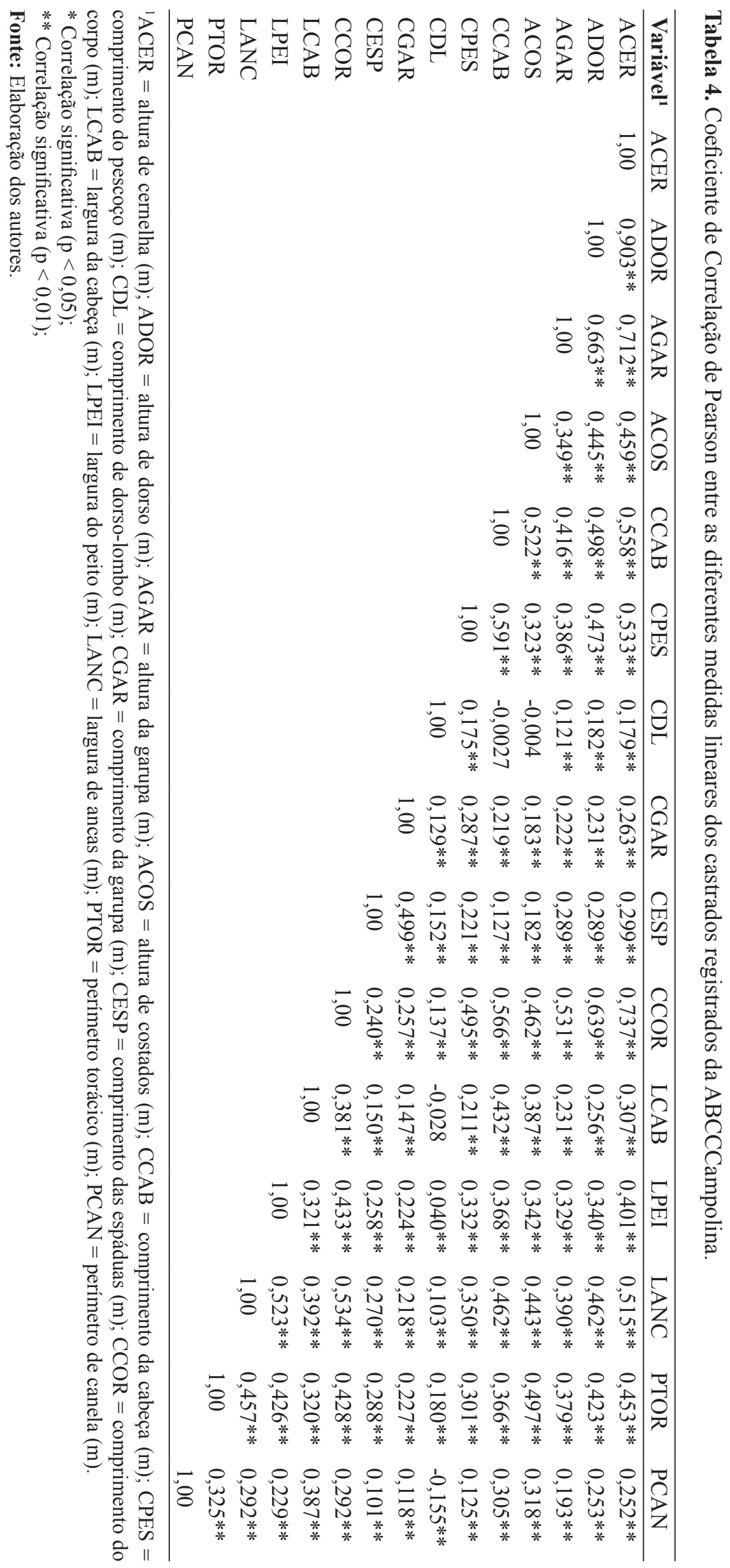




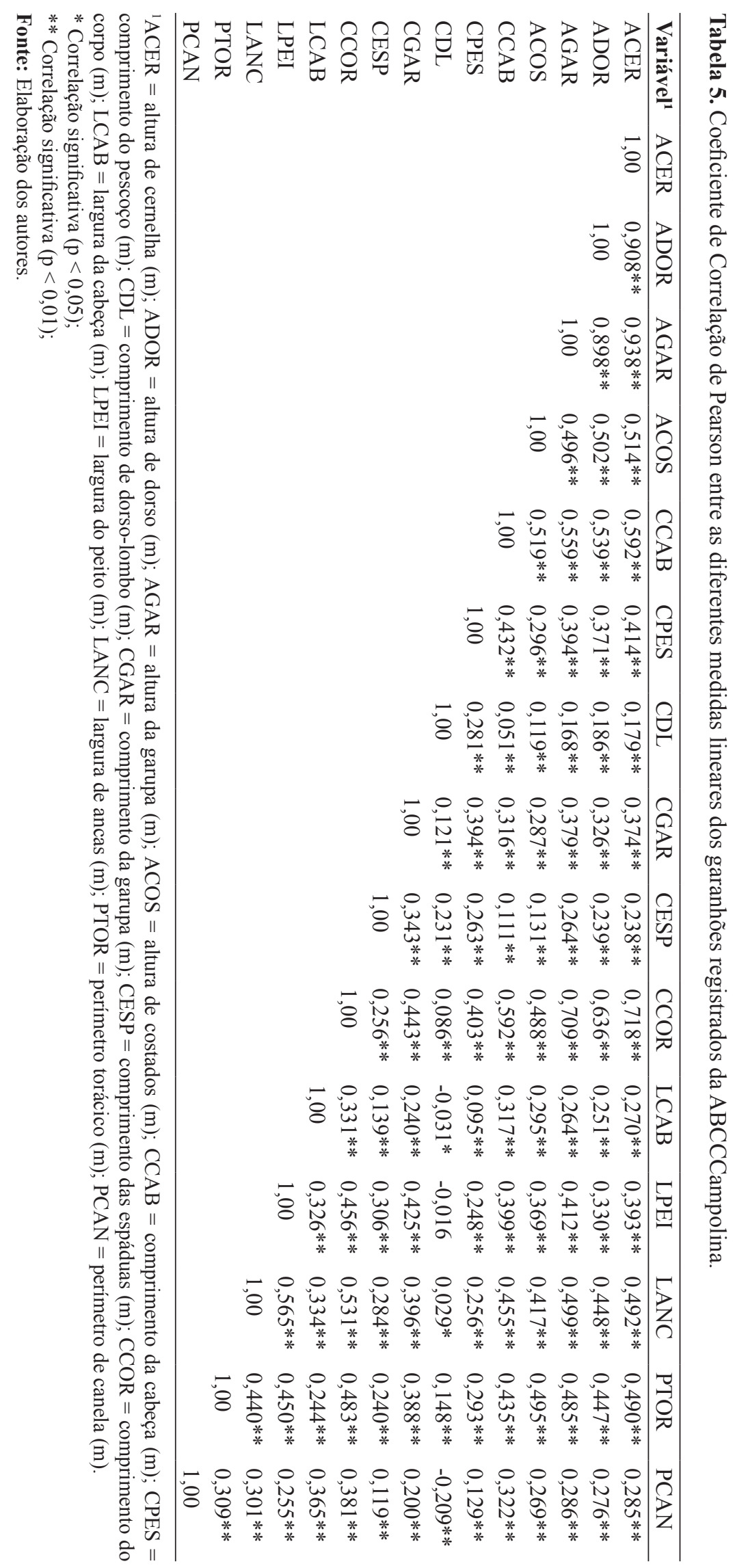


Tabela 6. P-valores associados às diferentes hipóteses avaliadas através do teste F (ANOVA) para as diferentes medidas lineares dos castrados e garanhões registrados da ABCCCampolina.

\begin{tabular}{|c|c|c|c|c|c|c|}
\hline \multirow{3}{*}{ Variável $^{1}$} & \multicolumn{3}{|c|}{ Castrados } & \multicolumn{3}{|c|}{ Garanhões } \\
\hline & \multicolumn{6}{|c|}{ Fonte de Variação } \\
\hline & Ano & Estado do Criatório & Pelagem & Ano & Estado do Criatório & Pelagem \\
\hline ACER & $0,0000 * *$ & $0,0010 * *$ & 0,0525 & $0,0000^{* *}$ & $0,0000^{* *}$ & $0,0000 * *$ \\
\hline ADOR & $0,0000 * *$ & 0,0846 & 0,0631 & $0,0000^{* *}$ & $0,0000 * *$ & $0,0000 * *$ \\
\hline AGAR & $0,0001 * *$ & $0,0000 * *$ & 0,0583 & $0,0000 * *$ & $0,0000 * *$ & $0,0000 * *$ \\
\hline $\mathrm{ACOS}$ & $0,0160^{*}$ & $0,0000 * *$ & 0,4082 & $0,0000^{* *}$ & $0,0000 * *$ & $0,0000 * *$ \\
\hline CCAB & $0,0000 * *$ & $0,0000 * *$ & 0,7525 & $0,0000 * *$ & $0,0000 * *$ & $0,0031 * *$ \\
\hline CPES & $0,0035^{* *}$ & $0,0000 * *$ & 0,5650 & $0,0000 * *$ & $0,0000 * *$ & $0,0385^{*}$ \\
\hline CDL & $0,0000 * *$ & $0,0000 * *$ & 0,2589 & $0,0000^{* *}$ & $0,0000 * *$ & $0,0038^{* *}$ \\
\hline CGAR & 0,2161 & $0,0000 * *$ & $0,0022 * *$ & $0,0000 * *$ & $0,0000 * *$ & $0,0250^{*}$ \\
\hline CESP & 0,0957 & $0,0000 * *$ & 0,8513 & $0,0000 * *$ & $0,0000 * *$ & 0,0880 \\
\hline CCOR & $0,0000 * *$ & 0,0685 & 0,1778 & $0,0000 * *$ & $0,0000 * *$ & $0,0000 * *$ \\
\hline LCAB & $0,0000 * *$ & $0,0000 * *$ & 0,7938 & $0,0000 * *$ & $0,0000 * *$ & 0,1845 \\
\hline LPEI & 0,1007 & $0,0000 * *$ & 0,1223 & $0,0000 * *$ & $0,0000 * *$ & $0,0076^{* *}$ \\
\hline LANC & $0,0060 * *$ & $0,0010 * *$ & 0,4045 & $0,0000 * *$ & $0,0000 * *$ & $0,0004 * *$ \\
\hline PTOR & 0,0592 & $0,0020 * *$ & 0,5504 & $0,0000 * *$ & $0,0000 * *$ & $0,0011 * *$ \\
\hline PCAN & $0,0000 * *$ & $0,0000^{* *}$ & 0,2594 & $0,0000 * *$ & $0,0000 * *$ & 0,3047 \\
\hline
\end{tabular}

${ }^{1} \mathrm{ACER}=$ altura de cernelha $(\mathrm{m}) ; \mathrm{ADOR}=$ altura de dorso $(\mathrm{m}) ; \mathrm{AGAR}=$ altura da garupa $(\mathrm{m}) ;$ ACOS = altura de costados $(\mathrm{m}) ;$ $\mathrm{CCAB}=$ comprimento da cabeça $(\mathrm{m})$; CPES = comprimento do pescoço (m); CDL = comprimento de dorso-lombo (m); CGAR = comprimento da garupa $(\mathrm{m}) ; \mathrm{CESP}=$ comprimento das espáduas $(\mathrm{m}) ; \mathrm{CCOR}=$ comprimento do corpo $(\mathrm{m}) ; \mathrm{LCAB}=1$ argura da cabeça $(\mathrm{m})$; LPEI = largura do peito $(\mathrm{m}) ; \mathrm{LANC}=$ largura de ancas $(\mathrm{m}) ;$ PTOR = perímetro torácico $(\mathrm{m}) ;$ PCAN = perímetro de canela $(\mathrm{m})$.

*Diferença Significativa $(\mathrm{P}<0,05)$;

**Diferença Significativa $(\mathrm{P}<0,01)$.

Fonte: Elaboração dos autores.

Para a fonte de variação estado do criatório, observa-se que para os animais castrados apenas a ADOR e o CCOR não apresentaram influência significativa $(\mathrm{P}<0,01)$ (Tabela 6). No entanto, observa-se que para os garanhões, todas as variáveis biométricas deste estudo, foram significativamente influenciadas $(\mathrm{P}<0,01)$ pelo estado do criatório (Tabela 6). Diferentemente, Berbari Neto (2005) em seu estudo com garanhões, observou que o PCAN não foi influenciado, para o mesmo grau de significância.

Em relação à variável pelagem nos animais castrados, apenas o CGAR foi influenciado $(\mathrm{P}<0,01)$. Ao passo que, para os garanhões a maioria das medidas foram influenciadas significativamente $(\mathrm{P}<0,01)$, excetuando-se as do CGAR e CPES, que foram significativamente influenciadas $(\mathrm{P}<0,05) \mathrm{e}$ as medidas PCAN, LCAB e CESP, que não foram influenciadas significativamente pela pelagem (Tabela 6). Berbari Neto (2005), para os garanhões da raça Campolina, só observou significância $(\mathrm{P}<0,01)$ em relação a ACER, ADOR e AGAR.

\section{Conclusões}

Os machos castrados da raça Campolina apresentaram-se melhor proporcionados que os garanhões, com base no CCAB, como preconizado por Lesbre, com as seguintes medidas lineares: ACER, CCOR, CPES, CDL, CGAR. Também foram bem proporcionados entre as medidas ACE:CCOR e CGAR:LANC. Contudo, apresentaram para as medidas lineares LPEI e ACOS valores abaixo do recomendado por Lesbre, para animais tipo sela, e valor de ACER menor que o preconizado, para 
machos, de acordo com o padrão da raça Campolina. Além disso, as correlações entre as medidas lineares encontradas neste estudo apresentaram valores mais baixos para os castrados que para os garanhões.

\section{Referências}

ASSOCIAÇÃO BRASILEIRA DOS CRIADORES DO CAVALO CAMPOLINA - ABCCC. Regulamento do serviço de registro genealógico e padrão racial. Belo Horizonte: ABCCCampolina, 1995. 18 p.

. Regulamento do serviço de registro genealógico e padrão racial. Belo Horizonte: ABCCCampolina, 2006. $18 \mathrm{p}$.

BARBOSA, C. G. Estudo morfométrico na raça Mangalarga Marchador. Uma abordagem multivariada. 1993. Dissertação (Mestrado em Zootecnia) Universidade Federal de Minas Gerais, Belo Horizonte.

BERBARI NETO, F. Análise das medidas lineares $e$ avaliação de índices morfométricos em garanhões da raça Campolina. 2005. Dissertação (Mestrado em Produção Animal) - Universidade Estadual do Norte Fluminense. Campos dos Goytacazes, Rio de Janeiro.

BRETAS, M. S. Associações entre características morfométricas e cinemáticas de equinos da raça Campolina. 2006. Dissertação (Mestrado em Zootecnia) - Universidade Federal de Minas Gerais, Belo Horizonte.

CABRAL, G. C. Avaliação morfométrica e estudo das curvas de crescimento de equinos da raça Mangalarga Marchador. 2002. Dissertação (Mestrado em Zootecnia) - Universidade Federal Rural do Rio de Janeiro, Seropédica.

CABRERA, L.; COSTA, P. E. M.; FONSECA, N. A. N. Efeito da castração pré-púbere sobre o desenvolvimento corporal de equinos. Acta Scientiarum Animal Sciences, Maringá, v. 26, n. 2, p. 273-279, 2004.
CAMPOS, C. C. Evolução de medidas lineares $e$ avaliação de índices morfométricos em fêmeas da raça Campolina. 2006. Dissertação (Mestrado em Produção Animal) - Universidade Estadual do Norte Fluminense. Campos dos Goytacazes, Rio de Janeiro.

COSTA, M. D.; BERGMANN, J. A. G.; PEREIRA, C. S.; RESENDE, A. S. C.; PEREIRA, J. C. C. Avaliação dos fatores genéticos e de ambiente que interferem nas medidas lineares dos pôneis da raça Brasileira. Revista Brasileira de Zootecnia, Viçosa, MG, v. 27, n. 3, p. 491497, 1998.

FONTES, L. R. Origem e características do cavalo Campolina. 1957. Tese (Professor Catedrático em Zootecnia) - Universidade Federal de Minas Gerais, Belo Horizonte.

LESBRE, F. X. Précis d'exterieur du cheval et des principanx domestiques. Paris: Vigot Frères, Éditeurs Paris. 1920. 500 p.

LITTELL, R. J.; FREUND, R. J.; SPECTOR, P. C. SAS system for linear models. 3. ed. Cary, NC: SAS Institute Inc., 1991.329 p.

OOM, M. M.; FERREIRA, J. C. Estudo biométrico do cavalo Alter. Revista Portuguesa de Ciências Veterinárias, Lisboa, v. 82, n. 482, p. 101-148, 1987.

REECE, W. O. Dukes: fisiologia dos animais domésticos. 12. ed. Rio de Janeiro: Guanabara Koogan S.A., 2006. 926 p.

SANTOS, R. F. O cavalo de sela brasileiro e outros equídeos. Botucatu: Editora Varela, 1981. 288 p.

SILVA, A. T. M. Hipologia, guia para o estudo do cavalo. Lisboa: Lidel Edições Técnicas, 2009. 323 p.

SILVA, R. G. Manual de procedimentos em análise por quadrados mínimos. Jaboticabal: Funep, 1993. 169 p.

TORRES, A. D. P.; JARDIM, W. R. Criação do cavalo e de outros equinos. São Paulo: Editora Nobel, 1992. 654 p.

VALE, R. C. O exterior do cavalo. 2. ed. São Paulo: Editora Manole, 1984. 96 p. 